\title{
La melcocha y el turismo vivencial, caso de estudio Baños de Agua Santa
}

\section{The route of the melcocha, Baños de Agua Santa 'study case}

1 Alisson Estefania Soria Torres

https://orcid.org/0000-0002-7836-6526.

Universidad Técnica de Ambato, Carrera de Turismo y Hotelería, Facultad de Ciencias

Humanas y de la Educación. Ambato, Ecuador.

asoria2222@uta.edu.ec

2 María Fernanda Viteri Toro

https://orcid.org/0000-0003-2600-7115

Universidad Técnica de Ambato, Carrera de Turismo y Hotelería, Facultad de Ciencias

Humanas y de la Educación. Ambato, Ecuador.

mf.viteri@uta.edu.ec

3 Daniel Oswaldo Sánchez Guerrero (iD) https://orcid.org/0000-0002-3104-9125.

Universidad Técnica de Ambato, Carrera de Turismo y Hotelería, Facultad de Ciencias

Humanas y de la Educación. Ambato, Ecuador.

do.sanchez@uta.edu.ec

4 Camilo Francisco Torres Oñate

Universidad Técnica de Ambato, Carrera de Turismo y Hotelería, Facultad de Ciencias

Humanas y de la Educación. Ambato, Ecuador.

cf.torres@uta.edu.ec

Artículo de Investigación Científica y Tecnológica

Enviado: 24/12/2021

Revisado: 29/12/2021

Aceptado:12/01/2022

Publicado:08/03/2023

DOI: https://doi.org/10.33262/concienciadigital.v6i1.4.2047

Cítese:

Soria Torres, A. E., Viteri Toro, M. F., Sánchez Guerrero, D. O., \& Torres Oñate, C. F. (2023). La melcocha y el turismo vivencial, caso de estudio Baños de Agua Santa. ConcienciaDigital, $6(1.4)$ 1013-1030.

https://doi.org/10.33262/concienciadigital.v6i1.4.2047

CONCIENCIA DIGITAL, es una Revista Multidisciplinar, Trimestral, que se publicará en soporte electrónico tiene como misión contribuir a la formación de profesionales competentes con visión humanística y crítica que sean capaces de exponer sus resultados investigativos y científicos en la misma medida que se promueva mediante su intervención cambios positivos en la sociedad. https://concienciadigital.org

La revista es editada por la Editorial Ciencia Digital (Editorial de prestigio registrada en la Cámara Ecuatoriana de Libro con No de Afiliación 663) www.celibro.org.ec 


\section{Palabras} claves:

Rutas gastronómicas, Valor gastronómico, Turismo vivencial.

Keywords:

Gastronomic route,

Gastronomic value, Experiential tourism.

\section{Resumen}

Introducción. La presente investigación está enfocada en el cantón Baños, puesto que se considera que la melcocha íntegramente forma parte de la gastronomía debido a que existen diferentes diseños, formas, texturas, tamaños, colores y sabores. Por esta razón se puede caracterizar a este producto como muy versátil, al mismo se le puede sacar mucho provecho y expandir una gran variedad en cuanto a generar algo nuevo y único que atrae al turista, logrando así que se pueda gestionar y aumentar las ventas debido a la atracción que produce el mismo en una de las ciudades más turísticas del Ecuador. Objetivo. Generar una propuesta de turismo vivencial basado en una ruta de la melcocha como producto gastronómico del cantón Baños. Metodología. Se desarrolla una investigación descriptiva, el cual se basa principalmente en describir características, recopilar y resaltar las cualidades de dicho fenómeno, debido a que se desea resaltar el valor gastronómico que posee la melcocha del cantón Baños y así generar una base para llamar la atención del turista y motivarlo a realizar un turismo vivencial. Resultados. La melcocha es un dulce representativo de la ciudad, debido a que éste llegara a definir las cualidades tanto del turismo vivencial en la experiencia para turistas que desean conocer el proceso de este manjar. Conclusión. Las rutas gastronómicas centran de manera prioritaria la idea de este nuevo tipo de turismo basadas en las experiencias inolvidables que promuevan el turismo en la ciudad.

\section{Abstract}

Introduction. This research is focused on the cantón Baños, where is considered that the melcocha is entirely part of the gastronomy because there are different designs, shapes, textures, sizes, colors and flavors. For this reason, it is possible to characterize this product as a very versatile one, and at the same time it is possible to achieve great objectives with it and generate something new and unique that attracts tourists, achieving that it can be managed and increased sales due to the attraction that is produced in one of the most touristic cities in Ecuador. Objective. Generate an experiential tourism proposal based on a melcochas route as a gastronomic product of cantón Baños. Methodology. Descriptive research is developed, which is based mainly on describing characteristics, compiling and highlighting the qualities of this 
phenomenon, because it is desired to highlight the gastronomic value that the melcocha of the cantón Baños has and generate a basis to attract the attention of the tourist and motivate them to carry out an experiential tourism. Results. The melcocha is a sweet representative of the city, because it will come to define the qualities of both experiential tourism in the experience for tourists who want to know the process of this delicacy. Conclusion. The gastronomic routes focus as a priority the idea of this new type of tourism based on unforgettable experiences that promote tourism in the city.

\section{Introducción}

$\mathrm{Su}$ origen e historia se remonta a los españoles que trajeron este arte culinario al Nuevo mundo Salvador (2018), menciona que la melcocha se conocía como una golosina de buena consistencia, debido a que resistía los viajes largos marítimos a diferencia del azúcar que se derrite o humedece, ya sea por el clima o el contacto con el agua. Además, que la palabra melcocha proviene de mel, que traducido significa miel; una miel muy concentrada correosa utilizado en la elaboración de confitería. Otro acercamiento a la melcocha nos remonta a Nueva España donde había la venta ambulante de este producto, los comerciantes deambulaban por comunidades y pueblos rurales si no la podían vender la cambiaban por diversos objetos según sus necesidades.

Ingredientes. - los ingredientes varían según el artesano Andrade (2017), pero lo más común para su elaboración es el agua, panela, aguardiente opcional, ralladura de limón, naranja o de mandarina, frutos secos como el maní, endulzantes y colorantes artificiales opcionales, concluyendo con la manipulación del caramelo, algunos artesanos les gusta propiciar un espectáculo del proceso de sobado con la distinguida degustación del producto fresco recién hecho. En la actualidad hay más opciones de componentes como colorantes, saborizantes, sustitutos de azúcar, entre otros, usados como ingredientes en las nuevas técnicas de elaboración de la melcocha, puesto que partimos de cosas básicas por así decirlo y ahora podemos incursionar en algo más complejo para el disfrute y deleite de los consumidores.

Proceso. - los procesos han sido parte de una herencia, cada familia las conoce y hace según sus conocimientos, la melcocha también llamada alfandoque o arropilla, siempre ha tenido un grado de popularidad muy notorio y existen en varios países de Latinoamérica.

Según Pérez (2020), los procesos y técnicas heredadas son empíricos y tradicionales; y actualmente sus procesos en el área de producción del producto implica que todo se realice con las manos, lo que asegura que siempre ha sido realizada artesanalmente por eso se dice que necesitamos de técnica, practica y mucha fuerza en el brazo, además de 
soportar el ambiente de altas temperaturas, debido a que se trabaja con panela que debe ser derretida a un grado específico para poder trabajarla y elaborarla.

Elaboración.- para comenzar con el proceso de la melcocha Rodríguez (2021), explica que se debe poner la panela en un olla con un poco de agua, este primer paso es para poder extraer la miel; una vez que ya tengamos la miel continuamos con el segundo paso que es cernirla por cualquier tipo de basura dentro de la panela o algún insecto, luego la pasamos a un bote en porciones pequeñas y procedemos a ponerla en otra olla a que hierva a más de 60 grados centígrados. Una vez concluido el primer paso procedemos a poner lo de la olla en una plancha metálica a esperar unos 10 a 15 minutos para que se enfríe la mezcla o sea la panela que hemos hecho miel, una vez que ya se enfríe y que se endurezca procedemos a hacer de endurecerla más en el gancho de que se jala la melcocha, ya fría seguimos al siguiente punto que es blanquearla. La melcocha luego de ser blanqueada debe reposar por unos minutos ya lo que son la mancha de color se lo hace de la misma manera, a un pedazo de melcocha se le agrega colorante mientras se le va amasando manualmente hasta que tenga el color requerido y ahí se le adhiere a pedazo grande de melcocha. Y culminamos con el proceso de la envoltura una vez que ya está envuelto podemos apreciar el proceso final de la melcocha pasamos a poner en una funda la sellamos y ya está listo para la venta. El proceso de elaboración puede ser difícil o complicado al principio, pero todo suele ser cuestión de práctica y se convertirá en algo súper sencillo, con base a la experiencia que se adquiere y según la creatividad del artesano. Para finalizar, es cubierto con papel transparente para proceder a su empaque. Así de fácil una vez aprendido el proceso de la melcocha casera, se puede seguir experimentando, ya que hasta la actualidad existen y se comparten las diferentes variedades con el sabor único y tradicional. Según Medina (2021), dice que algunos artesanos les gustan agregar ingredientes para realzar el sabor y se puede conseguir melcochas con diferentes frutos secos como las nueces. Así mismo se puede ofrecer más variedad en el aspecto visual al agregar colorantes para hacer de diferentes colores a este pequeño manjar.

Productores locales. - Baños tiene una población de 20.000 habitantes aproximadamente GAD. Municipal de Baños de Agua Santa (2019), menciona que se estima que una cuarta parte de la población se dedica a la melcocha, esto tomando en consideración que este producto ya se ha venido fabricando desde hace varias décadas atrás artesanalmente, por lo cual no se puede contar exactamente cuando comenzaron a elaborarlo, ni cuantas personas trabajan en esto, además se puede añadir que ha ido evolucionando y hoy en día es catalogado como un postre referente gastronómico del cantón.

Vendedores locales. - según Valencia (2011), dice que él fue uno de los primeros vendedores locales de melcochas, artesano nacido en Baños de Agua Santa, fue pionero en el arte de la elaboración de esta, cuenta que el enseño el proceso de elaboración a varias 
personas en esos tiempos, gracias a su esfuerzo y trabajo pudo emprender su propio negocio para salir adelante. Enfatiza que en su época él elaboraba los dulces en forma redonda, ahora son alargados y su presentación en general ha cambiado, pero que agradece lo aprendido porque no se complicó en seguir y adaptarse al cambio, cuenta también que la materia prima no es cara, lo difícil siempre ha sido y será la elaboración debido a la fuerza que se necesita, gracias a esto a sus 25 años creció convirtiéndose en una fábrica de dulces artesanales, además que en la actualidad hay muchos productos para comercializar como la panela, licor y arropes de frutas de la zona, entre otros.

Productos, luego de su elaboración se procede a dar cualquier forma, en barritas largas, trozos, anillos. Si se desea se presenta en forma de flores o perlas atractivas, los productos más conocidos son los alfeñiques, caramelos, paletas, palillos, bastones, dulces de guayaba, maní confitado y panela, siempre para una mejor conservación se la cubre con un plástico de protección. Los nuevos productos no solo dependen de la alegre y colorida decoración, sino del regalo ideal que llega a ser. Márquez (2018), expresa que así mismo se puede añadir que es cuestión de la empresa la decisión de innovar y cambiar formas, es decir, de una melcocha plana y común transformarla a rosas y canastas, puesto que los lleva a mejorar o crear nuevos productos que en el mercado no hay, tomando en consideración que juega mucho la creatividad.

Valor económico, las melcochas para la venta tiene un precio que va desde $\$ 0,50$ - $\$ 1,00$ hasta $\$ 5,00$ por cada fundita Merino (2018), expresa que sin embargo varía el tamaño y dulce que sea, este precio se mantiene debido a que no es costosa la materia prima, y cualquier persona puede acceder por el precio a cualquier producto que desee, debido a esto se da la aceptación de este dulce crocante, con este peculiar sabor que se puede encontrar en la ciudad.

Comercialización, la melcocha por ser tan versátil puede distribuirse sin problema a cualquier parte del país, sin embargo, no tenemos antecedentes de una correcta o adecuada comercialización sea dentro o fuera del país, la gente emprendedora no solo vende este producto así nomás, sino también recorre y cuenta tradiciones. Es una gran oportunidad de compartir esta delicia. Con respecto al ámbito financiero se puede llegar a la conclusión que es económicamente rentable. La comercialización de este producto Arias (2020) demuestra que se la realiza en mayor parte en el sector de llegada o salida de la ciudad, pero también se opta por vender dentro de la misma, ya que los visitantes se encuentran en cualquier parte de la ciudad debido a que siempre recibimos turistas nacionales y extranjeros, también se dio como opción vender en los transportes interprovinciales ya que los vendedores suben a los diferentes buses que pasan por la vía.

Tradiciones y celebraciones, Baños siempre ha sido catalogado como el centro turístico de los cuatro mundos: Mundo de aventura, descanso, diversión y naturaleza. Valencia (2012), expresa que esta es una de las fiestas que más invade el ambiente de la ciudad, 
puesto que es la fiesta más grande y concurrida por turistas nacionales y extranjeros, es la fiesta del carnaval de la caña, la melcocha y la alegría que se realiza en el mes de febrero, en donde se exhibe un desfile de color, belleza y sabor con bailes tradicionales con música y ritmos andinos y tropicales, carros alegóricos de hermosos colores, fruta y pequeñas melcochas que son entregadas durante el recorrido comparsas, reinas, danzantes y bandas de pueblo para la ciudadanía y turistas en general, que puedan ser parte de una de las celebraciones más bonitas y representativas de la ciudad que da su debido valor a cada detalle. Como bien sabemos Baños de Agua Santa vive del turismo, por lo cual se pretende atraer anualmente más o menos a 60.000 turistas a este festival, cabe aclarar que un aproximado del $95 \%$ de la población sea directa o indirectamente trabaja en la industria del turismo, por esta razón es que siempre se tiene un programa para esta festividad de 3 o 4 días de actividades culturales y entretenimiento y en general. Otra celebración tradicional son las fiestas Octubrinas, el vicealcalde Proaño (2019), menciona que estas son fiestas religiosas en homenaje a la Virgen del Rosario de Agua Santa, muchos turistas llegan durante todo el mes de octubre los diferentes barrios, parroquias y caseríos se reúnen y realizan diferentes actividades, como: la chicha, la pasada de flores y cirios, juegos populares, dulces melcochos, la procesión y la santa misa en cada sector. Se toma el tiempo debido para cada actividad puesto que es importante ser partícipes de todas. Una tradición importante del 15 de septiembre es presentar a la ciudadanía y turistas las melcochas y su preparación integral por parte del Baneño y la esencia de este, y es denominado como 'Baños ciudad de sabores', en donde se puede apreciar cómo se prepara este tradicional dulce, acompañado de un concurso de degustación de los diferentes productos. Según Silva (2018), alcalde de la ciudad manifiesta que es estrategia para que la gente conozca las tradiciones de una de las principales ciudades turísticas del Ecuador, y retomar las antiguas técnicas para que el turista se sienta atraído por aquello que no conoce como lo es la preparación de las mejores melcochas del país.

Importancia para el contexto de Baños. el proceso de elaboración le ha convertido a la melcocha en un producto merecedor de la gran aceptación que tienen en el mercado local y de igual manera la posibilidad de incursionar en un gran aumento de producción debido a que hay una creciente demanda del mismo, lo cual ha permitido que sea importante para el sector turístico debido a que actualmente este delicioso dulce y sus diferentes tipos son el objeto más llamativo y creativo según las exigencias y satisfacción del cliente en el mercado actual. Para Baños de Agua Santa Novoa (2015), menciona que cubrir la demanda de este producto ha sido un éxito sin ninguna complicación, debido a que en ésta radica la importancia en el desarrollo y la economía de una pequeña ciudad que cumple con la procedencia de los productos de calidad pertinente e igual forma la producción no ha tenido ningún inconveniente porque son productos caracterizados y conocidos regionalmente por los habitantes, la ciudadanía y por quienes la visitan. 
Aporte para el turismo del cantón Baños, Baños es conocida como la tierra de la caña y la melcocha, con gente emprendedora que fomento el turismo con la elaboración de la melcocha y sus demás servicios complementarios como: atractivos turísticos, termas, comida tradicional, entre otros. Es una de las ciudades del ecuador que se destaca por la oferta turística, todos los días llegan turistas, pero el número asciende especialmente en los fines de semana y feriados, aquí se acoge a turistas nacionales y extranjeros que buscan diversión, entretenimiento y descanso, el Ministerio de Turismo (2018), menciona que el turismo es una de las actividades más importantes para la ciudadanía porque se encuentra en constantes cambios, evolución e innovación. La gastronomía ecuatoriana ha sido por años relacionada al servicio turístico nacional, por lo cual una vez analizado los saberes ancestrales gastronómicos se pudo dar un impulso al turismo gastronómico de la ciudad de Baños, por lo tanto, se vincula al área turística, de diversión y entretenimiento con costumbres, festividades y tradiciones, manifestándose así la importancia combinada con las practicas culinarias, rituales y creencias. Puesto que también contamos con el turismo religioso en la ciudad y de igual manera influyen las interacciones, actitudes y comportamientos en el empoderamiento cultural de la ciudadanía con el fin de mejorar exponencialmente el turismo gastronómico local.

Gastronomía tradicional. la demanda de la gastronomía tradicional según Robalino (2016), depende de la motivación que tienen los turistas para llegar al punto de destino y probar una experiencia única gastronómica, Baños de Agua Santa es calificado como uno de los mejores destinos turísticos del Ecuador, considera que se realiza el turismo gastronómico, pese a que hay una variedad de restaurantes en la ciudad son pocos los que ofrecen platos tradicionales evidenciando así no sea mucha la demanda de este servicio que no se ha perdido el propósito de dar a conocer la oferta gastronómica. Cabe aclarar que la gastronomía es un punto importante en la actividad turística, el entorno y desarrollo de las actividades son con el fin de buscar satisfacer los requerimientos de los visitantes sean nacionales o extranjeros, por ende, los servicios complementarios como la gastronomía es vista y realizada de forma adecuada estableciendo niveles de calidad en la oferta de platos tradicionales evidenciando las características importantes de una experiencia sensorial. 


\section{Figura 1}

Modelo teórico de enfoque estructural de Inskeep

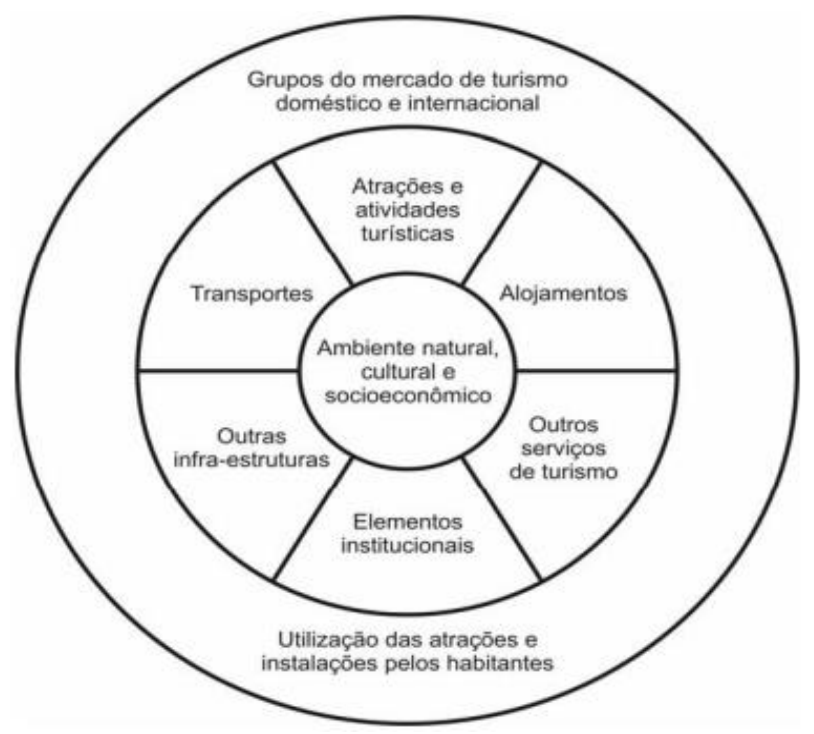

Fuente: Soria (2021)

Cabe recalcar que una de las principales cualidades es la capacidad de englobar algo tan pequeño que es la melcocha en algo tan grande como lo es la gastronomía, en ella se integran la economía y lo sociocultural en un proyecto sustentable que involucra a la sociedad local teniendo como objetivo mejorar la calidad de vida de la población a la par con identidades de desarrollo como sustentable y humano en la industria, para así partir de este enfoque y vincularlo con los conocimientos antiguos con los procesos de modernización.

\section{Metodología}

El presente estudio de la metodología aplicada que se llevó acabo es un diseño mixto, el alcance de la de la investigación fue descriptivo. Para el desarrollo de este se planteó 4 etapas, iniciando desde el levantamiento de la información en fichas, la realización del desarrollo de la encuesta y su respectiva validación e interpretación desde la hermenéutica del turista para caracteriza

\section{Etapa 1}

Fichas Instituto Nacional de Patrimonio Cultural (INPC)

La información reconectada es acerca de técnicas artesanales tradicionales, relacionada con sus tradiciones y dinamismo, especificando las actividades de carácter esencialmente manual que emplean instrumentos para la elaboración de un producto.

1. Datos de localización 
Área designada para señalar la localización geográfica detallada (provincia, cantón, parroquia, ciudad) del bien inmaterial, de acuerdo con la normalización vigente emitida por el INEC.

\section{Fotografía referencial}

Área que ilustra de manera fotográfica la manifestación inventariada y descripción de la fotografía

\section{Datos de identificación}

Área que permite colocar los datos específicos de la manifestación inventariada y los campos de clasificación en la que se ubica, así como un breve resumen descriptivo de la misma.

\section{Descripción}

Área para describir la manifestación inventariada, de una manera detallada y completa, con los datos etnográficos como resultado de la investigación de campo y otras fuentes.

\section{Portadores / soportes}

Área para identificar los datos básicos de los portadores de la manifestación, se refieren a las personas, colectividades o instituciones que han asumido roles de salvaguardia de los componentes de la cultura inmaterial.

\section{Valoración}

Área destinada para describir el carácter valorativo patrimonial que tanto los interlocutores como el investigador tienen sobre la manifestación inventariada.

\section{Interlocutores}

Área destinada para respaldar los datos personales de los interlocutores a fin de identificarlos y ubicarlos si fuese el caso.

\section{Elementos relacionados}

Área en la que se exponen otros elementos que intervienen de manera directa o indirecta en la manifestación inventariada, por ejemplo, creencias, tabúes ritualidades.

\section{Anexos}

Área en la que se deben incluir los materiales adicionales como los respaldos digitales de los anexos deberán estar organizados en archivos claramente identificados. 


\section{Observaciones}

Área destinada para comunicar hechos, experiencias novedosas, o cualquier dato adicional que sirvan como información relevante para reorientar su investigación.

\section{Datos de control}

Área para detallar nombres de entidades y personas que intervienen en el inventario y fechas respectivas, como constancia de su responsabilidad en el proceso.

El objetivo de las fichas es investigar los procesos que inciden en forma concomitante en la preservación, apropiación y uso adecuado del patrimonio cultural material e inmaterial, así como también destaca los conocimientos y saberes que se transmiten de generación en generación, de igual forma los objetos o productos de la actividad artesanal.

\section{Etapa 2}

Fichas del Atlas del Patrimonio Alimentario

Esta ficha permite conocer la técnica artesanal para la elaboración del producto final. Al ser aplicada ayuda a conocer de forma profunda los ingredientes primarios empleados en la elaboración de un producto final.

Productos primarios, nombre del producto, hace referencia a la forma tradicional con la que se denomina al producto elaborado y puede estar expresado en cualquier lengua nativa. Nombre común, información sobre las características de una planta o un animal, guiado por el sentido de observación, la imaginación, los sentimientos y hasta el sentido del humor. Nombre científico, cada organismo con características morfológicas únicas es conocido como especie; las especies con características similares forman un grupo llamado género.

Ancestralidad, da a conocer la forma de preparación de los alimentos según la cultura de cada pueblo. Nativos productos domesticados en Ecuador, prehispánicos no nativos son productos que no domesticados en Ecuador. Criollos: llegaron después de la conquista española y contemporánea: son aquellos productos que han llegado en el siglo XX

Descripción, aquí entra una descripción muy básica del producto, sin necesidad de entrar en detalles botánicos o zoológicos.

Imagen del producto, acoge una imagen del producto, que ayude a su rápida identificación.

Zonas de producción, esta sección se enlista las parroquias donde el producto es emblemático, junto con el nombre del cantón hay un recuadro más grande destinado a acoger un mapa de la provincia. 
Calendario agro festivo, son las actividades importantes asociadas al cultivo o la crianza: preparación del terreno, siembra y cosecha.

Usos gastronómicos, la alimentación ha sido desde siempre una práctica necesaria para los seres humanos, ya que comemos para sobrevivir.

Propiedades, es un listado simple de las propiedades nutritivas o medicinales atribuidas al producto.

Variedades y estado de conservación, hace referencia al estado de consumo del producto mediante una categorización: Común Cuando la especie o raza aún se encuentra con facilidad en los mercados o es comida normalmente en los hogares. Raro Cuando ya no se la consume regularmente o no se la encuentra con facilidad, pero no está en peligro de desaparecer. En peligro Cuando se hace muy difícil o imposible de encontrar, poca gente sabe dónde obtenerla o hay datos sobre su estado y estos señalan que se encuentra en peligro de desaparecer.

Ficha patrimonio alimentario son productos primarios, recogen la información en el campo de la investigación y a cada producto se le añade toda la información y datos encontrados sobre el mismo. Permite conocer más acerca de ese producto como: su taxonomía y derivados.

Se recolecta información de gran importancia, como el uso de los ingredientes tradicionales que hasta la actualidad son utilizados en las cocinas de los ecuatorianos, siendo el resultado de años de experimentación en busca de una mejor gastronomía. Se puede llegar a consumir ingredientes con gran sabor y alto valor nutricional importantes para el desarrollo humano.

\section{Etapa 3}

Encuesta

La encuesta desarrollada aporto al levantamiento de información, la cual está compuesta de 18 ítems con opciones de respuesta variadas, de los cuales 3 primeros ítems enfocados al área personal; posteriormente para el ámbito de conocimientos previos se desarrollaron 5 ítems con preguntas cerradas; de igual forma para el ámbito de importancia se conformó 4 ítems y para el ámbito de comercialización fue de 6 ítems determinando el interés y aceptación de una ruta gastronómica por parte de los turistas que visitan el destino turístico.

\section{Etapa 4}

Validación de instrumentos

Una vez estructurada la encuesta, se procedió a realizar una validación cualitativa por parte de docentes investigadores y profesionales inmersos en el área turística y hotelería, 
puesto que al ser este un proyecto investigativo se debe complementar y sustentar la encuesta bajo criterios académicos, se requería la validación de estos.

Tras receptar la respuesta por parte de los expertos, se continuó con la aplicación de este cumpliendo con cualquier corrección y modificación de los instrumentos, considerando las sugerencias por parte de estos, y manteniendo los criterios, objetivos y esencia de las variables que formaron parte de las encuestas.

Adicionalmente estadísticamente se obtuvo la fiabilidad del instrumento tras la aplicación del Alfa de Cronbach, mismo que determina el resultado del coeficiente de una totalidad de las aplicaciones para definir la ausencia de errores en el test. Su interpretación corresponde los siguientes datos:

Tabla 2

Interpretación de Cronbach

\begin{tabular}{ll}
\hline \multicolumn{1}{c}{ Variación numérica } & \multicolumn{1}{c}{ Interpretación } \\
\hline Entre $1,0-0,9$ & Instrumento de medición excelente \\
Entre $0,9-0,8$ & Instrumento bueno \\
Entre $0,8-0,7$ & Instrumento aceptable \\
Entre $0,7-0,6$ & Instrumento débil \\
Entre $0,6-0,5$ & Instrumento pobre \\
$<0,5$ & Instrumento no aceptable \\
\hline
\end{tabular}

Fuente: Coeficiente de Cronbach

Para fiabilidad del instrumento aplicado en base a la estadística de Alfa De Cronbach se lo determino con preguntas directas a las variables de estudio, obteniendo un análisis de 0,8 lo que se interpreta como un instrumento bueno.

\section{Tabla 3}

Análisis de fiabilidad

\begin{tabular}{c|c|c}
\hline $\begin{array}{c}\text { Alfa de } \\
\text { Cronbach }\end{array}$ & $\begin{array}{c}\text { Alfa de Cronbach basada en } \\
\text { elementos estandarizados }\end{array}$ & $\begin{array}{c}\text { N de } \\
\text { elementos }\end{array}$ \\
\hline .8 & .8 & 12 \\
\hline
\end{tabular}

Fuente: Programa estadístico SPSS

\section{Resultado}

\section{Etapa 1}

\section{Discusión fichas Instituto Nacional de Patrimonio Cultural (INPC)}

Tras el levantamiento de información para el conocimiento acerca de los productos elaborados en este casi se obtuvo datos relevantes para la investigación, los cuales detallan como es la elaboración con las técnicas ancestrales para el correcto desarrollo de estos. 
Etapa 2

\section{Discusión fichas del atlas del patrimonio alimentario}

La importancia de la realización de esta ficha radica en la parte simbólica, cultural e identidad para un país, ciudad o comunidad para ser considerada como patrimonio cultural alimentario y así trasmitir los elementos primarios de generación en generación conociendo un poco de su historia y usos en la sociedad.

\section{Etapa 3}

Discusión de la encuesta

\section{Tabla 4}

\section{Análisis de Resultados}

\begin{tabular}{|c|c|}
\hline Pregunta & Discusión \\
\hline \multicolumn{2}{|r|}{ AREA PERSONAL } \\
\hline $\begin{array}{l}\text { 1. ¿A qué rango de edad } \\
\text { pertenece? }\end{array}$ & $\begin{array}{l}\text { De las } 5 \text { opciones de respuesta, la edad de los turistas que visitan el cantón } \\
\text { Baños es del: } 5.1 \% \text { tiene menos de } 18 \text { años, el } 32.3 \% \text { tiene entre } 19-25 \\
\text { años, el } 32.8 \% \text { entre } 26-35 \text { años, el } 15.4 \% \text { tiene } 36-45 \text { años y el } 14.4 \% \\
\text { tiene más de } 45 \text { años, evidenciando que no fue exclusivo para un grupo } \\
\text { específico de edad. }\end{array}$ \\
\hline $\begin{array}{l}\text { 2. ¿A qué género } \\
\text { pertenece? }\end{array}$ & $\begin{array}{l}\text { En base a las encuestas realizadas el resultado total de encuestados es de un } \\
47.2 \% \text { en el género masculino y un } 52.8 \% \text { en el género femenino, probando } \\
\text { que no hay una gran diferencia entre ambos géneros y no predomina ninguno } \\
\text { de los dos. }\end{array}$ \\
\hline $\begin{array}{l}\text { 3. ¿A qué provincia } \\
\text { pertenece? }\end{array}$ & $\begin{array}{l}\text { Los resultados muestran que las personas que visitan el cantón llegan de las } \\
\text { siguientes provincias: el } 3.6 \% \text { de Bolívar, el } 1.5 \% \text { de Carchi, } 4.1 \% \text { de } \\
\text { Chimborazo, } 5.6 \% \text { de El Oro, } 6.7 \% \text { de Esmeraldas, } .5 \% \text { de las Galápagos, } \\
1.5 \% \text { de Loja, } 2.1 \% \text { de Los Ríos, } 1.5 \% \text { de Napo, } 1.5 \% \text { de Orellana, } 4.1 \% \text { de } \\
\text { Pastaza y } 1 \% \text { de Santo Domingo, demostrando que Cotopaxi con el } 13.3 \text {, } \\
\text { Guayas con el } 13.8 \text {, Tungurahua con el } 16.9 \text { y Pichincha con el } 22.1 \% \\
\text { predominan con los porcentajes más altos. }\end{array}$ \\
\hline
\end{tabular}

\section{CONOCIMIENTOS DE LA MELCOCHA}

4. ¿Conoce usted los En base a la totalidad de encuestados solo el $4.6 \%$ tiene total conocimiento, ingredientes de la mientras el $28.7 \%$ tiene conocimientos, el $21 \%$ esta inseguro, el $23.1 \%$ tiene melcocha? pocos conocimientos y el $23.6 \%$ desconoce los materiales para la elaboración de este producto, siendo estos los porcentajes más altos indiscutiblemente no está claro cuáles son los ingredientes.

5. ¿Conoce usted el En base a la tabla de frecuencia los resultados de las encuestas manifiestan proceso de elaboración que del $100 \%$ de encuestados el $4.1 \%$ tiene total conocimiento, siendo que de la melcocha? porcentaje más bajo en conocer una técnica artesanal ancestral, mientras que el $31.3 \%$ tiene conocimientos, el $17.4 \%$ esta inseguro, el $24.1 \%$ tiene pocos conocimientos y el $23.1 \%$ desconoce cómo es la elaboración de este producto.

6. ¿Estaría interesado/a Este resultado muestra evidentemente que el producto tiene un interés del en adquirir melcochas y sus derivados? $50.8 \%$ que probablemente sí adquieren este producto, mientras que el $10.3 \%$ no está seguro, el $5.6 \%$ probablemente no le interesa y el $1 \%$ definitivamente no está interesado siendo porcentajes bajos en comparación.

\begin{tabular}{l|l}
\hline 7. ¿Qué tipos de & En base a los diferentes productos, los encuestados respondieron que el \\
melcochas consume & $\begin{array}{l}12.3 \% \text { bastones, el 5.6\% paletas y el 13.3\% maní confutado, es decir que } \\
\text { sobresalen con un 30.3\% consume alfeñiques y un 38.5\% caramelos de } \\
\text { habitualmente? }\end{array}$ \\
& melcocha siendo las más conocidas y aceptadas por los visitantes. \\
\hline
\end{tabular}




\section{Tabla 4}

\section{Análisis de Resultados (continuación)}

\begin{tabular}{|c|c|}
\hline Pregunta & \\
\hline \multicolumn{2}{|r|}{ CONOCIMIENTOS DE LA MELCOCHA } \\
\hline $\begin{array}{l}\text { 8. En general, ¿cómo } \\
\text { calificaría a la } \\
\text { melcocha? }\end{array}$ & $\begin{array}{l}\text { La tabla de frecuencia demuestra que se puede evidenciar una calificación } \\
\text { del } 54.4 \% \text { como buena para los usuarios que consumen este producto y tiene } \\
\text { relación con el } 30.8 \% \text { que la califica como excelente, teniendo una gran } \\
\text { aceptación de este. }\end{array}$ \\
\hline \multicolumn{2}{|r|}{ IMPORTANCIA DE LA MELCOCHA } \\
\hline $\begin{array}{l}\text { 9. ¿Qué tan satisfecho } \\
\text { está con los diferentes } \\
\text { tipos de melcochas? }\end{array}$ & $\begin{array}{l}\text { De la totalidad de personas encuestadas se prueba que de las } 5 \text { opciones de } \\
\text { respuesta los encuestados mencionan que el } 54.9 \% \text { está satisfecho, a } \\
\text { continuación, le siguen porcentajes similares en cuanto al } 23.1 \% \text { muy } \\
\text { satisfecho y el } 20.5 \text { se siente neutral en relación con la satisfacción de este } \\
\text { producto. }\end{array}$ \\
\hline $\begin{array}{l}\text { 10. ¿Cuándo fue la } \\
\text { última vez que adquirió } \\
\text { este producto? }\end{array}$ & $\begin{array}{l}\text { En base al tiempo los encuestados manifiestan que el } 42.6 \% \text { que es el } \\
\text { porcentaje más alto adquirió este producto hace menos de } 1 \text { mes, seguido del } \\
26.7 \% \text { que fue de } 1 \text { - } 6 \text { meses y por último el } 19.5 \% \text { que fue de } 6 \text { meses a } 1 \\
\text { año que probo este producto por última vez, evidenciando así que hay una } \\
\text { relación oferta - demanda y viceversa. }\end{array}$ \\
\hline $\begin{array}{l}\text { 11. ¿Qué es lo que } \\
\text { encuentra mejor de este } \\
\text { producto? }\end{array}$ & $\begin{array}{l}\text { Tras observar los resultados de la encuesta, la tabla de frecuencia indica que } \\
\text { el porcentaje más alto que es del } 64.6 \% \text { siendo indiscutiblemente que el sabor } \\
\text { predomina ante las diferentes opciones de respuesta, mientras que el } 14.4 \% \\
\text { es por la fácil accesibilidad, el } 10.3 \% \text { por el diseño y el } 10.8 \% \text { por la } \\
\text { creatividad del producto. }\end{array}$ \\
\hline $\begin{array}{l}\text { 12. ¿Considera usted a la } \\
\text { melcocha como un dulce } \\
\text { recuerdo u obsequio } \\
\text { para regalar como } \\
\text { muestra de a ver visitado } \\
\text { el cantón? }\end{array}$ & $\begin{array}{l}\text { La tabla de frecuencia muestra dos grandes porcentajes en cuanto a lo que los } \\
\text { encuestados manifiestan el } 38.7 \% \text { está totalmente de acuerdo y el } 53.1 \% \text { está } \\
\text { de acuerdo, por lo tanto, la importancia que representa un dulce el obsequiar } \\
\text { un dulce detalle animando a la parte emocional del visitante. }\end{array}$ \\
\hline \multicolumn{2}{|r|}{ COMERCIALIZACIÓN DE LA MELCOCHA } \\
\hline $\begin{array}{l}\text { 13. ¿Conocía usted que } \\
\text { Baños de Agua Santa es } \\
\text { el mayor exportador de } \\
\text { melcochas del país? }\end{array}$ & $\begin{array}{l}\text { Luego de observar la tabla de frecuencia, la totalidad de encuestados } \\
\text { respondieron que el } 44.1 \% \text { tiene conocimientos siendo el porcentaje que } \\
\text { predomina ante el } 13.3 \% \text { que tiene total conocimiento, el } 16.4 \% \text { que esta } \\
\text { inseguro, el } 11.8 \% \text { tiene pocos conocimientos y el } 14.4 \% \text { que desconoce la } \\
\text { comercialización de este producto. }\end{array}$ \\
\hline $\begin{array}{l}14 . \quad \text { Para su } \\
\text { próxima compra, ¿qué } \\
\text { probabilidades hay de } \\
\text { que vuelva adquirir este } \\
\text { producto? }\end{array}$ & $\begin{array}{l}\text { Los resultados de los encuestados demuestran que para el } 48.7 \% \text { es algo } \\
\text { probable de igual manera para el } 36.9 \% \text { es muy probable que se vuelva } \\
\text { adquirir este producto por parte de los visitantes, sin verse afectado por el } \\
11.3 \% \text { no está seguro, el } 1 \% \text { es algo poco probable y para el } 2 \% \text { es muy poco } \\
\text { probable adquirirlo de nuevo. }\end{array}$ \\
\hline $\begin{array}{l}\text { 15. ¿Recomendaría las } \\
\text { melcochas del cantón } \\
\text { Baños? }\end{array}$ & $\begin{array}{l}\text { De las } 5 \text { opciones de respuesta según los encuestados el resultado muestra } \\
\text { que hay una gran aceptación del el } 53.8 \% \text { de estar seguros en recomendar } \\
\text { este producto del cantón baños específicamente y de igual manera el } 37 \% \\
\text { probablemente sí cuenten con el apoyo y aceptación de este. }\end{array}$ \\
\hline \begin{tabular}{lcr}
16. & \multicolumn{3}{c}{ ¿Le gustaría ser } \\
partícipe & de & la \\
elaboración & de & la \\
melcocha? & &
\end{tabular} & $\begin{array}{l}\text { Del total de encuestados en la tabla de frecuencia se evidencia una gran } \\
\text { aceptación acerca de esta idea con el } 54.1 \% \text { de acuerdo de la mano del } 27.3 \% \\
\text { está totalmente de acuerdo con aprender nuevos conocimientos y } \\
\text { experiencias de algo único de lo cual pueden ser partícipes. }\end{array}$ \\
\hline
\end{tabular}


Tabla 4

Análisis de Resultados (continuación)

\begin{tabular}{|c|c|}
\hline Pregunta & Discusión \\
\hline & COMERCIALIZACIÓN DE LA MELCOCHA \\
\hline 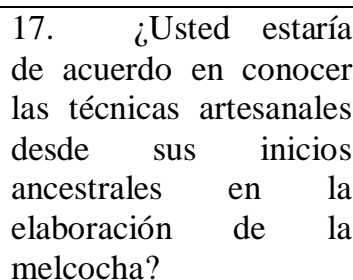 & $\begin{array}{l}\text { Tras observar los resultados de la totalidad de encuestados indica que el } \\
53.8 \% \text { está de acuerdo, al igual que } 33.8 \% \text { que está totalmente de acuerdo en } \\
\text { conocer las técnicas artesanales heredades ancestralmente gracias a los } \\
\text { primeros melcocheros; en comparación al } 9.7 \% \text { que está indeciso, el } 1.5 \% \\
\text { está en desacuerdo y el 1\% está totalmente en desacuerdo con la pregunta. }\end{array}$ \\
\hline $\begin{array}{l}\text { 18. ¿Considera } \\
\text { usted importante la } \\
\text { creación de una ruta } \\
\text { gastronómica sobre } \\
\text { elaboración de la } \\
\text { melcocha en el cantón } \\
\text { Baños? }\end{array}$ & $\begin{array}{l}\text { En base a las opciones de respuesta los encuestados evidencian que este } \\
\text { planteamiento tiene una gran aceptación del } 52.3 \% \text { de acuerdo, al igual que } \\
\text { el } 38.5 \% \text { está totalmente de acuerdo, el } 8.7 \% \text { está indeciso y el } 0.5 \% \text { está } \\
\text { totalmente en desacuerdo con la creación de una ruta gastronómica sobre la } \\
\text { elaboración de la melcocha en la ciudad turística de Baños. }\end{array}$ \\
\hline
\end{tabular}

Fuente: Soria (2021)

\section{Conclusiones}

- La investigación permite establecer que en el cantón de Baños no se aprecia como tal a la melcocha dentro de la gastronomía, siendo este un producto versátil al cual se le puede obtener mucho provecho y expandir una gran variedad en cuanto a generar algo nuevo y único que atrae al turista, por lo cual se piensa desarrollar "La Ruta de la melcocha".

- Para la ciudadanía una ruta alimentaria representa una gran importancia e impacto para la revalorización de un producto que genera fuentes de ingresos indiscutibles debido al alto consumo por parte de turistas, mejorando así la economía de una de las ciudades más turísticas del Ecuador.

- La gastronomía es una actividad relacionada con ingredientes, recetas y técnicas, en este caso se mantienen técnicas ancestrales y artesanales para realizar la melcocha que tiene gran aceptación, debido a una gran afluencia de viajeros, que buscan degustar de este producto, caramelos y jugo de caña que se elaboran en base a la caña de azúcar, gracias a sus múltiples presentaciones derivados del mismo las hacen las más famosas y también conocidas como las mejores melcochas del Ecuador en el pedacito de cielo.

- La denominada "La Ruta de la melcocha" trae el imaginario colectivo de una estrategia alternativa en cuanto a dar a conocer un turismo vivencial basado en la elaboración y fabricación de la melcocha como producto gastronómico a diferencia de solo adquirir un producto sin conocer ni ser parte de este, ofertando y comercializando principalmente en el contexto de una experiencia única y deferente. 


\section{Referencia Bibliográfica}

Andrade, C. (11 de abril de 2017). Noticias Ecuador. Obtenido de Melcochas de Panela: https://noticiasec.com/melcochas-de-panela-receta-y-preparacion/

Arias, S. (26 de septiembre de 2020). Ecuador travel. Obtenido de https://ecuador.travel/press/una-dulce-experiencia-con-manjares-ecuatorianos/

GAD. Municipal de Baños de Agua Santa. (2019). Municipiobanos.gob.ec. Obtenido de https://municipiobanos.gob.ec/banos/images/LOTAIP2020/junio2020/PDOT_20 19-2023-BORRADOR.pdf

Márquez, C. (06 de septiembre de 2018). El caramelo artesanal es la especialidad. Obtenido de Revista Líder: https://www.revistalideres.ec/lideres/carameloartesanal-especialidad-bolivarecuador-produccion.html

Medina, C. (10 de Julio de 2021). Qué noticias. Cómo se preparan las melcochas en Baños de Agua Santa, en Tungurahua, una tradición que pasa de padres a hijos, págs. https://quenoticias.com/noticias/melcochas-ecuador-recetas/.

Merino, A. (2018). Productos que ofrece la parroquia San José de Alluriquín. Library, 44-50.

Ministerio de Turismo. (2018). Turismo.gob.ec. Obtenido de https://www.turismo.gob.ec/banos-un-carismatico-y-tranquilo-lugar-al-pie-deun-volcan/

Novoa, C. (15 de marzo de 2015). El telégrafo. Obtenido de https://www.eltelegrafo.com.ec/noticias/con/1/el-dulce-de-guayaba-unagolosina-patentada-en-banos

Pérez, I. (25 de septiembre de 2020). Decoraciones de Tortas. Obtenido de https://decoraciondetortasweb.com/como-hacer-melcocha-de-panela-receta/

Proaño, A. (20 de octubre de 2019). Baños-Ecuador. Obtenido de https://banosecuador.com/es-ec/tungurahua/banos-de-agua-santa/fiestas-religiosas/fiestasoctubrinas-banos-afj114tf0

Robalino, J. (2016). Incidencia de la gastronomía para elegir un destino. Caso de estudio: Baños de Agua Santa. Tungurahua-Ecuador. Conciencia Digital. 
Rodríguez, S. (27 de Julio de 2021). Video en contexto. Obtenido de https://videoencontexto.com/2021/07/proceso-y-elaboracion-de-las-melcochasparroquia-alluriquin-kevin-stalin/

Salvador, F. (18 de Julio de 2018). Los canastos. Obtenido de Historia de la Melcocha: dulce típico: https://www.loscanastos.me/post/2018/07/18/historia-de-lamelcocha-dulce-t $\%$ C $3 \%$ ADpico

Silva, L. (10 de septiembre de 2018). La hora. Obtenido de https://lahora.com.ec/tungurahua/noticia/1102184899/inicia-el-mes-del-turismoen-banos-de-agua-santa-

Valencia, D. (22 de febrero de 2012). Baños Ecuador. Obtenido de http://banosecuador.com/banos-el-destino-turistico-ideal-en-los-feriados/

Valencia, J. (04 de diciembre de 2011). La hora. Obtenido de https://lahora.com.ec/noticia/1101246396/don-jorge-el-primero-en-vendermelcochas

\section{Ciencia Ligital}


El artículo que se publica es de exclusiva responsabilidad de los autores y no necesariamente reflejan el pensamiento de la Revista Conciencia Digital.

\section{Ciencia
Digital
Eutroul}

El artículo queda en propiedad de la revista y, por tanto, su publicación parcial y/o total en otro medio tiene que ser autorizado por el director de la Revista Conciencia Digital.
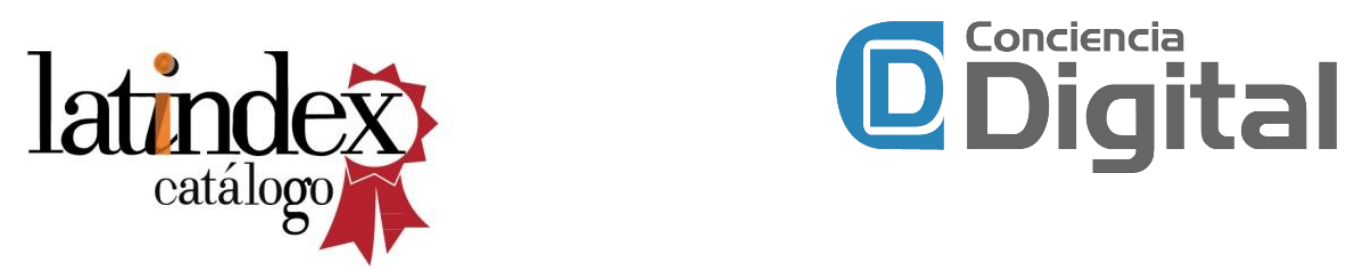

Indexaciones

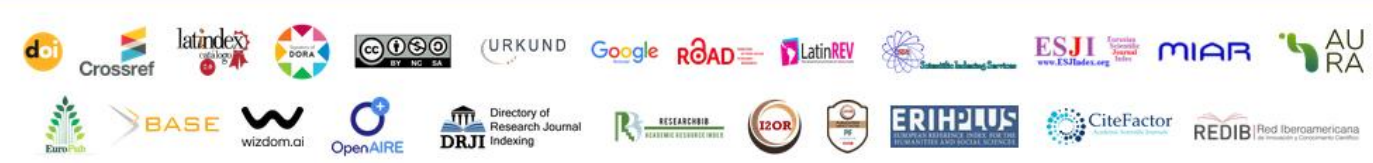

